\title{
A Study on the Soil Respiration in Cutting and Uncutting Areas of Larix leptolepis Plantation
}

\section{Kyu-Jin Lee and Hyeong-Tae Mun*}

Department of Biology, Kongju National University, Kongju 314-701, Korea

Received June 9, 2010 /Accepted August 27, 2010

\begin{abstract}
Quantification of the ecosystem respiration is essential in understanding the carbon cycling of natural and disturbed landscapes. Soil respiration and some environmental factors which affect soil respiration were investigated in a Larix leptolepis plantation inKongju, Korea. Soil respiration was measured at midday of the $15^{\text {th }}$ and $30^{\text {th }}$ day of every month from May to December in a non-cutting area (Control) and a cutting area (Treatment) with IRGA Soil Respiration Analyzer. Throughout the study period, average soil temperature and water content were $23.3 \pm 0.5^{\circ} \mathrm{C}$ and $27.76 \pm 7.12 \%$ for control, and $25.9 \pm 3.1^{\circ} \mathrm{C}$ and $24.55 \pm 5.12 \%$ for treatment, respectively. There was a positive correlation $\left(\mathrm{R}^{2}=0.8905\right)$ between soil respiration and soil temperature in the study area. However, there was no significant correlation between soil respiration and soil moisture $\left(\mathrm{R}^{2}=0.4437\right)$. The seasonal soil respiration increased in the summer and decreased in the winter. In August, maximum soil respirations in the control and treatment areas were $0.82 \pm 0.13$ and $1.32 \pm 0.10 \mathrm{gCO}_{2} \cdot{ }^{-2} \cdot \mathrm{r}^{-1}$, respectively. Total amounts of $\mathrm{CO}_{2}$ evolution in the control and treatment areas from May to December in 2008 were 2,419.2 and 3,610.8 $\mathrm{CO}_{2} \mathrm{~g} \cdot \mathrm{m}^{-2}$, respectively. The amount of soil respiration in the treatment area was $49.3 \%$ greater than in the control. Increased soil respiration in the treatment area may be due to increased soil temperature, which drives increased microbial decomposition. According to our present investigation, forest cutting will increase the atmospheric $\mathrm{CO}_{2}$ by increasing soil respiration.
\end{abstract}

Key words : $\mathrm{CO}_{2}$ evolution, cutting area, Larix leptolepis, soil respiration, soil temperature

\section{서 론}

산림토양은 생태계 탄소수지의 중요한 구성원이며, 다량의 탄소 저장능력을 통해 증가하고 있는 대기 중 이산화탄소를 저감시키는 중요한 역할을 하고 있다[20]. 이산화탄소는 자연 적 그리고 인위적 활동을 통해 방출되는 중요한 온실가스 중 의 하나이다[10]. 대기 중 이산화탄소의 증가 원인은 화석연료 의 연소가 가장 중요하지만 삼림의 벌목도 대기 중 이산화탄 소 증가의 중요한 요인이 되고 있다[16,25].

삼림은 광합성을 통해 대기 중으로부터 탄소를 흡수하여 유기물을 합성한 다음 일부를 식물의 각 기관에 저장하며, 나 머지는 호흡을 통해 대기 중으로 방출한다. 잎에 저장되는 탄 소는 낙엽으로 임상에 이입되어 토양유기물로 전환되며, 이들 탄소는 유기물의 분해과정인 토양미생물의 호흡을 통해 대기 중으로 방출된다[21]. 토양호흡은 토양 미생물의 호흡과 뿌리 의 호흡에 의해 발생되는데, 토양호흡에 영향을 주는 환경요 인으로는 토양온도, 토양수분, 유기물 함량 등이 알려져 있다 $[14,22,23]$. 토양미생물의 활성은 삼림생태계의 낙엽분해과정 에 중요한 부분을 차지하며, 미생물의 활동에 의한 낙엽의 무 기화과정은 삼림생태계 물질생산에 필요한 영양염류 공급의

*Corresponding author Tel : +82-41-850-8499, Fax : +82-

E-mail : htmun@kongju.ac.kr:
기본이 된다[18]. 토양호흡은 토양미생물 활성의 지표가 되기 때문에 삼림생태계의 탄소순환을 이해하는데 중요한 요인이 된다[10]. 최근에 전 세계적으로 많은 지역에서 벌목이 이루어 지고 있고, 이러한 생태계의 교란은 토양호흡에 영향을 주는 환경요인을 변화시켜 그 지역의 탄소 순환에 영향을 줄 수 있다 $[9,28]$.

본 연구의 목적은 삼림생태계의 탄소수지 파악을 위한 기초 연구의 일환으로 일본잎갈나무 조림지를 대상으로 토양호흡 을 측정하여 토양호흡에 대한 토양온도와 토양수분의 영향을 평가하고, 벌목과 같은 인위적 교란에 의한 환경 변화에 따른 토양호흡량의 변화를 파악하기 위한 것이다.

\section{재료 및 방법}

\section{조사지 개황}

본 연구의 조사지인 일본잎갈나무 조림지는 행정구역상 충 남 공주시 반포면 봉곡리에 위치하고 있다. 일본잎갈나무 (Larix leptolepis) 조림지에서 벌목지(처리구)와 비벌목지 대조 구)를 조사지소로 선정하였다. 대조구인 일본잎갈나무 조림지 의 수령은 35 40년, 교목의 평균 흥고직경은 $18.4 \mathrm{~cm}$, 평균 수고는 $15.5 \mathrm{~m}$, 그리고 임목밀도는 1,500 그루/ha이었다. 하층 관목으로는 쪽동백나무(Styrax obassia), 국수나무(Stephanandra incisa), 생강나무(Lindera obtusiloba), 개옻나무(Rhus tricho- 
carpa) 등이 낮은 밀도로 분포하고 있으며, 초본층의 피도는 $10 \%$ 정도로 낮았다. 임상은 연중 $3 \sim 4 \mathrm{~cm}$ 의 낙엽층으로 덮여 있었다. 처리구인 벌목지의 경우 벌목으로 인해 지상부의 일 본잎갈나무가 제거되어 칡(Pueraria thunbergiana), 땅비싸리 (Indigofera kirilowii), 싸리(Lespedexa bicolor), 엉겅퀴(Cirsium japonicum var. ussuriense) 등의 초본층 피도가 높게 나타났다. 조사기간인 2008년 한 해 동안 조사지역의 강수량 및 월별 평균기온은 조사지소에서 약 $32 \mathrm{~km}$ 떨어져 있는 부여측후소 의 자료를 참조하였다. 조사기간 동안(2008년 5월부터 12 월)의 강수량은 $770.3 \mathrm{~mm} / \mathrm{yr}$, 최 난월은 7 월 $26.3^{\circ} \mathrm{C}$, 최 한월은 12 월 의 $1.2^{\circ} \mathrm{C}$ 이었다(Fig. 1 ).

\section{토양호흡 측정}

토양호흡은 2008년 5월부터 12월까지 월 2회씩(15일과 30 일) 11:00 13:00 사이에 대조구와 처리구에서 각각 5 지소를 선정하여 IRGA 토양호흡 측정기(EGM-4, PPsystem)를 사용 하여 측정하였다. 대조구와 처리구별 호흡량 평균치의 차이는 SPSS 통계프로그램을 이용하여 T-test를 실시하였다.

\section{토양온도, 토양 채취 및 분석}

토양호흡에 영향을 미치는 가장 중요한 환경요인으로 토양 온도가 알려져 있다. 본 연구에서는 대조구, 처리구 지역에서 토양 호흡량을 측정하면서 토양온도를 측정하였다. 토양온도 는 T\&D Thermo Recorder를 사용하여 조사기간 동안 매일 1 시간 간격으로 자동으로 측정하였다. 온도기록계 본체에 연 결된 sensor는 지표로부터 $5 \mathrm{~cm}$ 깊이에 묻어 깊이에 따른 온도 변화를 측정하였다. 토양호흡 측정과 함께 0-10 cm의 상층토 양을 채취하였다. 토양은 비닐봉투에 밀봉하여 실험실로 운반 한 후 수분함량을 측정하였다. 토양의 수분함량은 fresh soil을

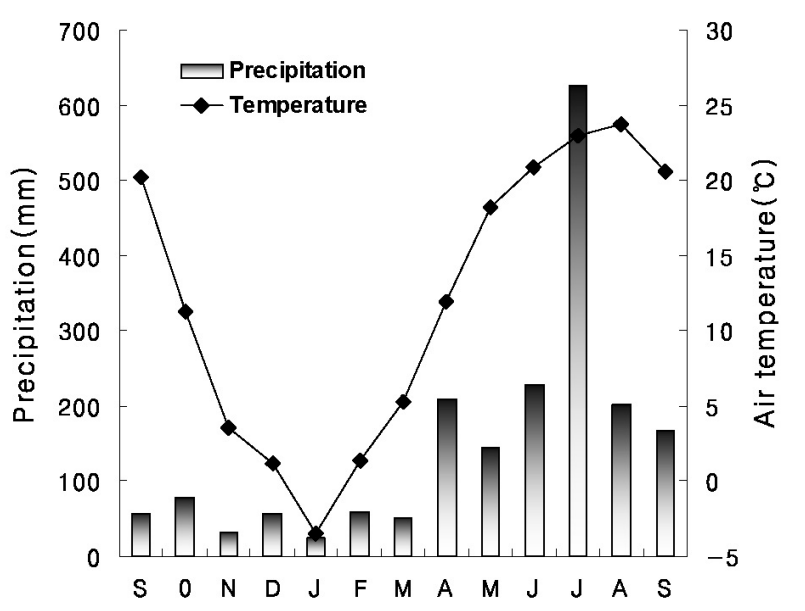

Month

Fig. 1. Seasonal precipitation and average monthly temperature in 2008 at Buyeo meterological station about $32 \mathrm{~km}$ distance from the study area. $105^{\circ} \mathrm{C}$ 건조기에서 48 시간 이상 항량이 될 때까지 건조시킨 후 칭량하여 소실된 수분을 fresh soil에 대한 \%로 나타내었다.

\section{결과 및 고찰}

\section{토양온도와 수분함량}

조사지역의 대조구와 처리구에서 토양온도의 계절변화 패 턴은 매우 유사하게 나타났다. 대조구와 처리구의 지표면 최 대온도는 모두 8월 중에 측정되었으며, 평균온도는 대조구와 처리구에서 각각 $23.3 \pm 0.5,25.9 \pm 3.1^{\circ} \mathrm{C}$ 로 대조구에 비해 처리 구에서 $2.6^{\circ} \mathrm{C}$ 높게 나타났다(Fig. 2A). 지표면의 최소온도는 12 월 중에 대조구와 처리구에서 각각 $4.0 \pm 0.6,6.1 \pm 3.4^{\circ} \mathrm{C}$ 로 기 록되었다. 대조구와 처리구에서 조사기간 동안의 연평균 지표 면 온도는 각각 $15.9,17.7^{\circ} \mathrm{C}$ 로 대조구보다 처리구에서 높게 나타났다.

조사기간 동안 대조구와 처리구의 평균 토양수분함량은 각 각 $27.76 \pm 7.12,24.55 \pm 1.40 \%$ 로 나타났으며(Fig. 2B), 대조구가 처리구에 비해 수분함량이 높은 것으로 나타났다. 토양수분함 량은 대조구에서 8 월 $(38.68 \pm 3.55 \%)$ 에 가장 높았고, 12 월 $(18.60 \pm 1.65 \%)$ 에 가장 낮았다. 처리구에서도 8 월 $(31.8 \pm 3.88 \%)$ 에 가장 높았고, 12 월 $(18.1 \pm 1.54 \%)$ 에 가장 낮았다. 지소간 계절 별 토양수분함량의 차이는 벌목에 따른 광량 증가와 토양온도 변화에 의한 수분의 손실에 의한 것으로 사료된다 $[8,20,25]$.
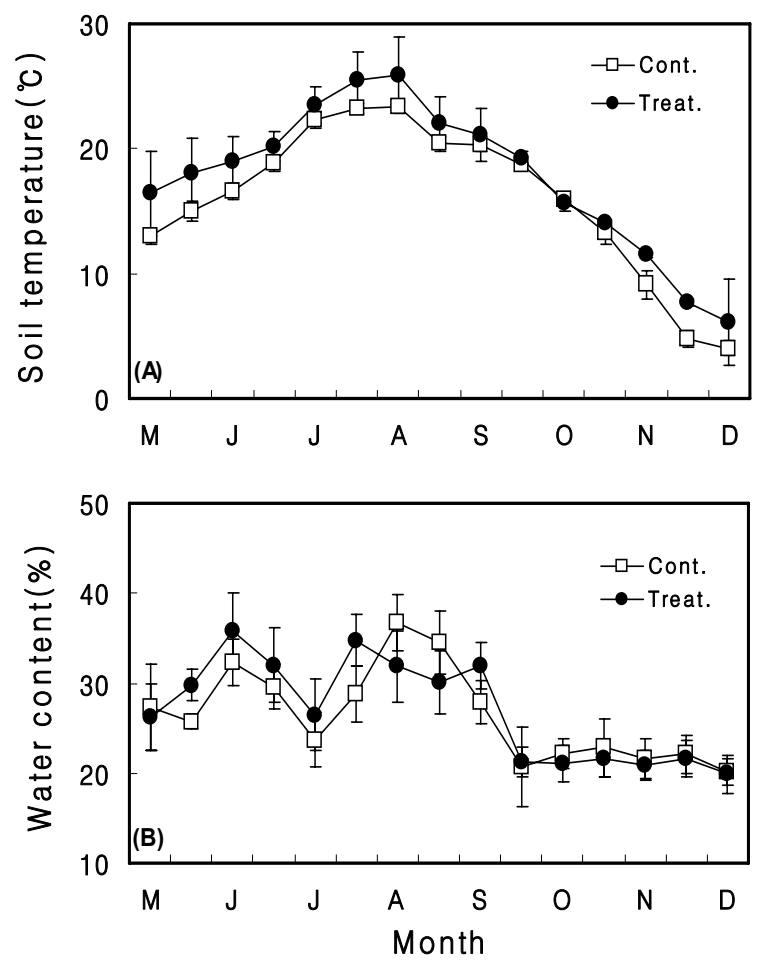

Fig. 2. Seasonal soil temperature (A) and soil water content (B) at the Larix leptolepis plantation. Cont; uncutting area, Treat; cutting area. 


\section{토양호흡량}

대조구와 처리구의 토양호흡량은 모두 하절기로 감에따라 증가한 뒤 동절기로 갈수록 감소하는 경향을 보였다(Fig. 3). 조사기간 동안 대조구와 처리구의 평균 토양호흡량은 각각 $0.43 \pm 0.27,0.67 \pm 0.48 \mathrm{gCO}_{2} \cdot \mathrm{m}^{-2} \cdot \mathrm{hr}^{-1}$ 로 처리구가 대조구에 비해 유의하게 높게 나타났다 $(\mathrm{p}<0.01)$. 토양호흡량이 가장 높은 8월 에 대조구와 처리구의 평균 토양호흡량은 각각 $0.82 \pm 0.13$, $1.32 \pm 0.10 \mathrm{gCO}_{2} \cdot \mathrm{m}^{-2} \cdot \mathrm{hr}^{-1}$ 로 처리구가 대조구에 비해 높게 나타 났으나, 12 월에는 토양호흡량이 각각 $0.03 \pm 0.02,0.03 \pm 0.01$ $\mathrm{gCO}_{2} \cdot \mathrm{m}^{-2} \cdot \mathrm{hr}^{-1}$ 로 지소간에 유의한 차이는 없었다.

조사기간 동안인 2008년 5월부터 12월까지 대조구와 처리 구의 총 토양호흡량은 각각 $2.42,3.61 \mathrm{kgCO} \cdot \mathrm{m}^{-2}$ 로 처리구가 대조구에 비해 $49.3 \%$ 높게 나타났다(Table 1). 계절별 토양호 흡량의 변화는 토양온도의 계절변화와 매우 유사하게 7 8월 에 최고치에 도달한 후 점차 감소하는 경향을 나타내었다.

국내의 리기다소나무림과 낙엽송림에서 5월에서 12 월까지 측정한 토양호흡량은 $1.68 \sim 1.94 \mathrm{kgCO} \cdot \mathrm{m}^{-2}$ 으로 본 조사지역 의 결과에 비해 낮았으며[26], 일본의 40 년생 소나무림에서의 연간 토양호흡량은 $3.6 \mathrm{kgCO} 2 \cdot \mathrm{m}^{-2} \cdot \mathrm{yr}^{-1}$ 으로 본 조사지소 처리

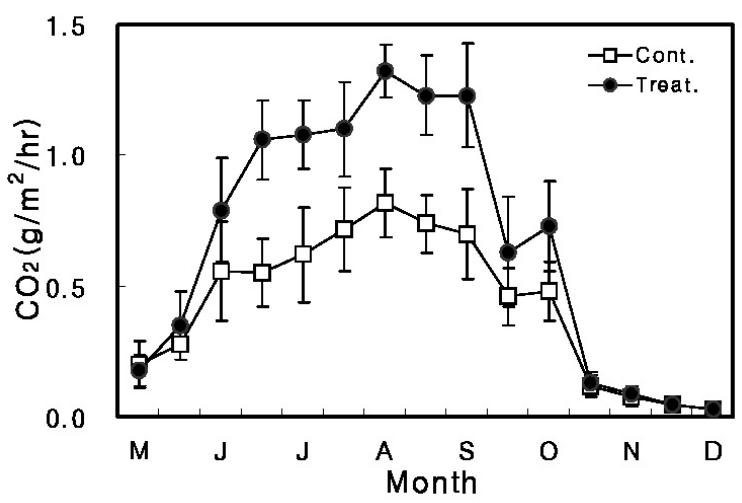

Fig. 3. Seasonal $\mathrm{CO}_{2}$ evolution at the Larix leptolepis plantation. Cont: uncutting area, Treat: cutting area.

Table 1. Seasonal amount of soil $\mathrm{CO}_{2}$ evolution in uncutting and cutting plots in the Larix leptolepis plantation in 2008

\begin{tabular}{ccc}
\hline \multirow{2}{*}{ Month } & \multicolumn{2}{c}{$\mathrm{CO}_{2} \mathrm{~g} \cdot \mathrm{m}^{-2} \cdot \mathrm{mo}^{-1}$} \\
\cline { 2 - 3 } & Uncutting & Cutting \\
\hline May & 172.80 & 190.80 \\
Jun. & 399.60 & 666.00 \\
Jul. & 482.40 & 784.80 \\
Aug. & 561.60 & 918.00 \\
Sep. & 518.40 & 669.60 \\
Oct. & 216.00 & 309.60 \\
Nov. & 46.80 & 50.40 \\
Dec. & 21.60 & 21.60 \\
Toal & $2,419.20$ & $3,610.80$ \\
\hline
\end{tabular}

구의 결과와 유사하였다[18]. 조사기간 동안 대조구와 처리구 에서 측정된 총 토양호흡량은 유사 기후대에서 조사된 결과와 차이를 보였으나[26], 본 조사의 결과는 전 세계 침엽수림의 토양에서 발생되는 토양호흡량 $\left(1.0 \sim 4.6 \mathrm{kgCO} \cdot \mathrm{m}^{-2} \cdot \mathrm{yr}^{-1}\right)$ 의 범 위 내에 포함되는 값이었다[22].

생태계의 탄소순환에서 토양호흡의 중요성이 대두된 이후 많은 사람들이 다양한 기후대와 식생형에서 토양호흡을 측정 하였다 $[8,12,24,27]$. 토양호흡에 관한 대부분의 연구에서 토양 호흡이 1 차적으로 토양온도에 의해 주도되며, 이들 사이에 상 당히 높은 상관관계가 있음을 보고하였다[13,14,17,26,29,30]. 삼림 토양의 온도는 유기물질의 분해율과 미생물에 의해 매개 되는 물질순환 과정에 영향을 미치는 주된 요인이며, 뿌리 호 흡과도 밀접한 관련이 있다[2,11,15]. 본 연구에서도 교란의 정 도와 상관없이 토양호흡과 토양온도 사이에 높은 상관관계를 나타내었다. 토양호흡률은 동절기에서 하절기로 갈수록 토양 온도가 증가함에 따라 지수적으로 증가하였다(Fig. $4 \mathrm{~A}$ ). 본 조 사지소에서 토양온도와 토양호흡률 사이의 상관관계는 $\mathrm{R}^{2}=0.8905$ 로 유의성이 매우 높게 나타났다.

토양수분과 토양호흡의 관계에 대해서는 연구에 따라 서로 다른 결과가 보고되고 있다[8,19,20,24,27]. 이들 연구에서는 토 양수분을 토양호흡을 결정하는 2차적인 환경요인으로 평가하 였고, Alaska 내륙지역의 성숙한 삼림에서 연구 보고된 결과
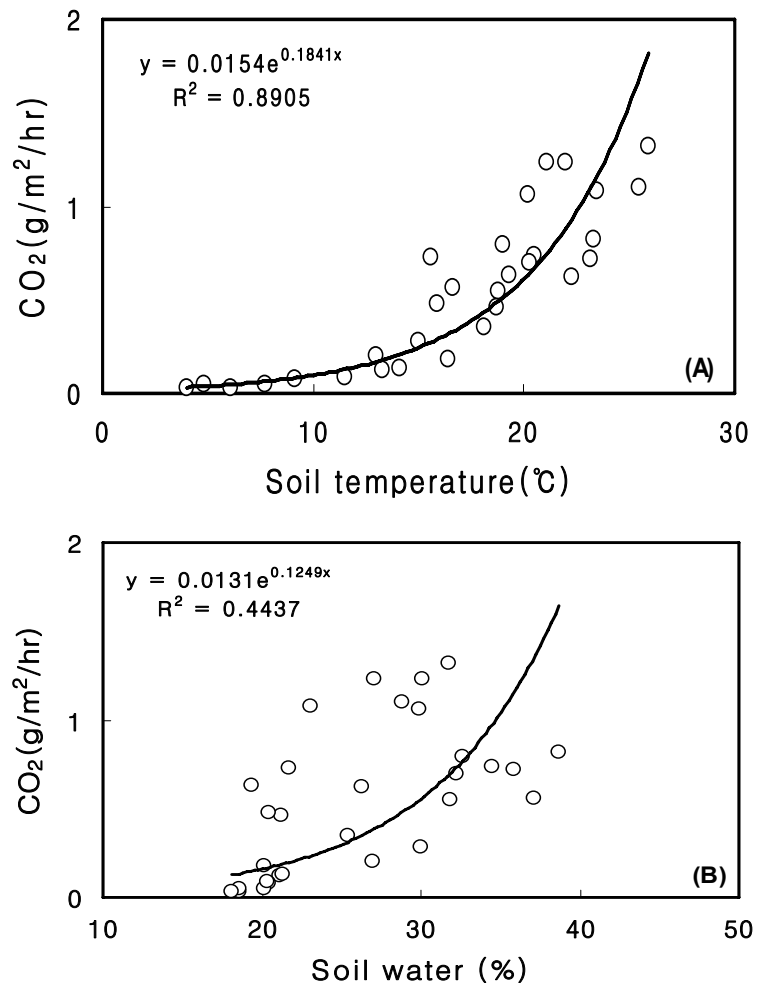

Fig. 4. The relationship between soil respiration and soil temperature (A), and between soil respiration and soil water(\%) in the Larix leptolepis plantation. 
에 의하면 토양온도에 따라 토양수분이 이산화탄소의 발생량 에 영향을 주어 $10 \sim 20^{\circ} \mathrm{C}$ 사이의 토양온도에서 토양습도가 중요한 요인이 된다고 하였다[24]. 그 외의 연구는 토양수분과 토양호흡량 사이에 관련성이 적다고 보고된 바 있다[3,4]. 본 조사결과에서도 토양수분과 토양호흡량 간에는 상관관계가 낮은 것으로 나타났으며, 토양수분과 호흡량 사이의 상관계수 는 $R^{2}=0.4437$ 로 토양온도에 비해 토양호흡과의 유의성이 낮았 다(Fig. 4B).

본 실험결과 벌목지인 처리구에서 대조구에 비해 토양호흡 량이 높게 나타났다. 이는 벌목으로 인해 토양호흡에 주 영향 을 주는 토양온도의 변화에서 비롯된 것으로 판단된다 $[20,27,30]$. 또한 벌목 후 진행되는 2 차 천이과정에서 이입된 콩과식물의 질소고정으로 인해 무기질소 이용도가 증가함에 따른 미생물의 활성 증가에도 일부 원인이 있을 수 있다[5,6]. 또한 벌목으로 인하여 하층 초본식생이 증가되어 표층토에 분포하는 세근의 양 증가에 따른 뿌리호흡의 증가도 처리구에 서 토양호흡량 증가의 원인이 될 수 있다[5,7]. 토양의 무기질 소 증가가 뿌리나 미생물의 활성을 증가시킬 경우 호흡량은 증가할 수 있지만, 무기질소 증가가 토양호흡에 미치는 효과 는 단기적 그리고 장기적으로 다르게 나타날 수 있다[5,6]. 그 러나 장기적으로 질소함량이 증가할 경우 오히려 미생물의 활성이 감소되어 토양호흡량이 감소될 수 있다[27].

본 연구에서는 대조구와 처리구 사이에 토양호흡량에 차이 가 나타난 것이 1 차적으로 벌목에 의한 토양온도 증가에 의한 것으로 판단된다. 일반적으로 벌목과 같은 삼림생태계의 교란 은 토양의 유기물질 분해를 촉진시켜 토양에 저장되어 있는 유기탄소가 대기 중으로 방출되는 것을 촉진시키는 것으로 알려져 있다[1,8]. 따라서 벌목과 같은 산림생태계의 교란이 탄소순환에 미치는 영향을 파악하기 위해서는 토양호흡에 영 향을 주는 토양온도뿐만 아니라 교란으로 인한 토양미생물 활성, 임상 토양의 양분 변화 등에 대한 연구가 필요하다고 판단된다.

\section{References}

1. Berg, B. and R. Laskowski. 2006. Litter decomposition: A guide to carbon and nutrient turnover. Elsevier, New York.

2. Bonan, G. B. and K. Van Cleve. 1991. Soil temperature, nitrogen mineralization and carbon source-sink relationships in boreal forest. Can. J. For. Res. 22, 629-639.

3. Bremner, J. L. and T. G. Huntington. 1995. The effects of temperature and moisture on dormant season soil respiration in a southern piedmont forest. Agron. Abst. pp. 309.

4. Bridgham, S. D. and C. J. Richardson. 1992. Mechanisms controlling soil respiration $\left(\mathrm{CO}_{2}\right.$ and $\left.\mathrm{CH}_{4}\right)$ in southern peatlands. Soil Biol. Biochem. 24, 1089-1099.

5. Ceulemans, R., I. A. Janssens, and M. E. Jach. 1999. Effects of enrichment on trees and forests: Lessons to be learned in view of future ecosystem studies. Annals of Botany 84, 577-590.

6. Choi, J. S. and H. T. Mun. 2004. Effects of nitrogen addition on soil respiration. Korean J. Ecol. 27, 155-159.

7. Crapo, N. L. and D. C. Coleman. 1972. Root distribution and respiration in a Carolina old field. Oikos 23, 137-139.

8. Gordon, A. M., R. E Schlentner, and K. Van Cleve. 1987. Seasonal patterns of soil respiration and $\mathrm{CO}_{2}$ evolution following harvesting in the white spruce forests of interior Alaska. Can. J. For. Res. 17, 304-310.

9. Harmon, M. E., W. K. Ferrel, and J. F. Franklin. 1990. Effects of carbon storage on conversion of old-growth forests to youbg forests. Science 247, 699-702.

10. Kimble, J. M., L. S. Heath, R. A. Birdsey, and R. Lal. 2003. pp. 429, The potential of U.S. forest soils to sequester carbon and mitigate the greenhouse effect. CRC Press, New York.

11. Knapp, A. K., S. L. Conard, and J. M. Blair. 1998. Detemination of soil $\mathrm{CO}_{2}$ flux from a subhumid glassland: Effects of fire and fire history. Ecological Application 4, 760-770.

12. Kursar, T. A. 1989. Evolution of soil respiration and soil $\mathrm{CO}_{2}$ concentration in a lowland moist forest in Panama. Plant Soil 113, 19-21.

13. Lee, Y. Y. and H. T. Mun. 2001. A study on the soil respirationin Quercus acutissima forest. Korean J. Ecol. 24, 141-147.

14. Lloyd, J. and J. A. Taylor. 1994. On the temperature dependence of soil respiration. Functional Ecol. 8, 315-323.

15. MacDonald, N. W., D. R. Zak, and K. S. Pregitzer. 1995. Temperature effects on kinetics of microbial respiration and net nitrogen and sulfur mineralization. Soil Sci. Soc. Am. J. 59, 223-240.

16. Maier, C. A. and L. W. Kress. 2000. Soil $\mathrm{CO}_{2}$ evolution and root respiration in 11year-old loblolly pine (Pinus taeda) plantations as affected by mositure and nutrient availability. Can. J. For. Res. 30, 347-359.

17. McHale, P. J., M. J. Mitchell, and F. P. Bowles. 1998. Soil warming in a northern hardwood forest: trace gas fluxes and leaf litter decomposition. Can. J. For. Res. 28, 1365-1372.

18. Nakane, K. 1995. Soil carbon cycling in a Japanese cedar (Cryptomeria japonica) plantation. For. Ecol. Manag. 72, 185-197.

19. Pacific, V. J., B. L. McGlynn, D. A. Riveros-Iregui, D. L. Welsch, and H. E. Epstein. 2008. Variability in soil respiration across riparian-hillslope transitions. Biogeochem. 91, 51-70.

20. Popescu, O. 2001. Soil carbon dioxide efflux in a naturally regenerated and a planted clear-cut on the Virginia Piedmont. Thesis for Master Degree. Blacksburg. Virginia.

21. Pregitzer, K. S. 2003. Carbon cycling in forest ecosystems with anemphasis on belowground processes, pp. 93-107, In Kimble, J. M., L. S. Heath, R. A. Birdsey, and R. Lal (eds.), The potential of U.S. forest soils to sequester carbon and mitigate the greenhouse effect. CRC Press, New York.

22. Raich, J. W. and C. S. Potter. 1995. Global patterns of carbon dioxide emission from soils. Global Biochemical Cycles 9, 23-36. 
23. Reiners, W. A. 1968. Carbon dioxide evolution from the floor of three Minesota forest. Ecol. 49, 471-483.

24. Schlentner, R. E. and K. Van Cleve. 1985. Relationships between $\mathrm{CO}_{2}$ evolution from soil, substrate temperature and substrate moisture in four mature forest types in interior Alaska. Can. J. For. Res. 15, 97-106.

25. Schmel, D. S. 1995. Terrestrial ecosystems and the carbon cycle. Global Change Biol. 1, 77-91.

26. Son, Y. H. and H. W. Kim. 1996. Soil respiration in Pinus rigida and Larix leptolepis plantation. J. Kor. For. Soc. 85, 496-505.

27. Striegl, R. G. and K. P. Wickland. 1998. Effects of a clear-cut harvest on soil respiration in a jack pine lichen woodland. Can. J. For. Res. 28, 534-539.

28. Tans, P. P., I. Y. Fung, and T. Takahashi. 1990. Observational constraints on the global atmospheric $\mathrm{CO}_{2}$ budget. Science 247, 1431-1438.

29. Vose, J. M., K. J. Elliott, D. W. Johnson, R. F. Walker, M. G., Johnson, and D. T. Tingey. 1995. Effects of elevated $\mathrm{CO}_{2}$ and $\mathrm{N}$ fertilization on soil respiration from ponderosa pine (Pinus ponderosa) in open-top chambers. Can. J. For. Res. 25, 1243-1251.

30. Witkamp, M. 1969. Cycles of temperature and carbon dioxide evolution from the forest floor. Ecol. 47, 492-494.

\section{초록 : 잎갈나무조림지의 벌목지와 비벌목지의 토양호흡에 관한 연구}

\section{이규진 · 문형태*}

(공주대학교 생물학과)

공주 근교의 일본잎갈나무 조림지에서 벌목이 이루어지지 않은 비벌목지를 대조구, 벌목이 이루어진 벌목지를 처리구로 설정하여 토양호흡과 호흡에 영향을 주는 토양온도, 토양수분을 2008년 5월부터 12월까지 2주 간격으로 측정하였다. 조사기간 동안 대조구와 처리구의 평균 토양온도는 각각 $23.3 \pm 0.5^{\circ} \mathrm{C}, 25.9 \pm 3.1^{\circ} \mathrm{C}$ 으로 처리구에서 높 았으며, 토양수분은 각각 $27.76 \pm 7.12 \%, 24.55 \pm 5.12 \%$ 으로 처리구에서 낮게 나타났다. 토양호흡량은 봄부터 하절기 로 이행함에 따라 증가한 후 동절기에 이르기까지 감소하는 경향을 보였으며, 토양호흡과 토양온도와는 높은 상 관관계 $\left(\mathrm{R}^{2}=0.8747\right)$ 가 있었으나, 토양수분과는 유의성이 높지 않았다 $\left(\mathrm{R}^{2}=0.4437\right)$. 토양호흡량은 대조구와 처리구에 서 모두 8월에 가장 높았으며, 이때 대조구와 처리구의 평균 토양호흡량은 각각 $0.82 \pm 0.13,1.32 \pm 0.10 \mathrm{CO}_{2}$ $\mathrm{g} \cdot \mathrm{m}^{-2} \cdot \mathrm{hr}^{-1}$ 으로 나타났다. 대조구와 처리구에서 5 월부터 12 월까지 측정된 전체 호흡량은 각각 $2,419.2,3,610.8 \mathrm{CO}_{2}$ $\mathrm{g} \cdot \mathrm{m}^{-2}$ 으로 대조구에 비해 처리구에서 $49.3 \%$ 높은 것으로 나타났다. 본 연구의 결과 인위적인 삼림의 벌목은 토양 호흡량을 증가시켜 대기 중의 이산화탄소를 증가시킬 것으로 판단된다. 